\title{
Optimasi Penggunaan Sistem Preparasi Berbantuan Gelombang Mikro pada Analisis Logam Timbal dalam Ikan Tuna Kemasan Kaleng secara Spektrofotometri Serapan Atom
}

\author{
Magdalena Bitha ${ }^{* a}$, Jefri M. Winokan ${ }^{a}$
}

a Kimia, FMIPA, Universitas Negeri Manado, Tondano, 95619, Indonesia

\begin{tabular}{l} 
IN F O A R T I K E L \\
\hline Diterima 27 September 2020 \\
Disetujui 25 Oktober 2020 \\
\hline Key word: \\
Canned tuna \\
Microwave digestion \\
Lead \\
FAAS \\
\hline Kata kunci: \\
Tuna kemasan kaleng \\
Destruksi microwave \\
Timbal \\
SSA-nyala
\end{tabular}

*e-mail: lenabitha@gmail.com

\begin{abstract}
A BSTRACT
In this paper, an efficient and rapid acid digestion method using microwave preparation system (MPS Titan 100) was to optimize and validate for determination of Lead content in canned tuna sample. The sample were digested in 6 variation of acids combination including $\mathrm{HNO}_{3}, \mathrm{H}_{2} \mathrm{O}_{2}$, and $\mathrm{H}_{2} \mathrm{SO}_{4}$. The digested samples were subjected to flame atomic absorption spectrophotometer for determination of Lead. The method was validated for linearity, precision, accuracy, limit of detection and limit of quantification. The optimized method showed good regression, $r=0.9997$. The limit of detection and limit of quantification were found to be $0.54446 \mathrm{ppm}$ and $1.8148 \mathrm{ppm}$, respectively. Precision of the method was checked by \% RSD with result $0.27 \%$. Accuracy of the method was indicated by \% recovery study and resulting $109.24 \%$ for Lead analysis. This analytical results were agreed well, as confirmed by the accepted range according to standards and guidelines. This procedure was applied to the determination lead in canned tuna sample and resulting 0.6951 ppm for A sample, 0,4634 ppm for B sample and 0.7073 ppm for C sample.
\end{abstract}

\section{A BSTRAK}

Penelitian ini mengoptimasi dan memvalidasi metode destruksi asam yang efisien dan cepat menggunakan sistem preparasi gelombang mikro (MPS Titan 100) untuk penentuan Timbal dalam sampel ikan tuna kemasan kaleng. Sampel didestruksi menggunakan 6 variasi kombinasi asam yang terdiri atas $\mathrm{HNO}_{3}, \mathrm{H}_{2} \mathrm{O}_{2}$, and $\mathrm{H}_{2} \mathrm{SO}_{4}$. Sampel yang telah terdestruksi dianalisis menggunakan spektrofotometer serapan atom nyala. Parameter uji untuk validasi metode ini meliputi linearitas, presisi, akurasi, batas deteksi dan batas kuantifikasi. Metode yang optimum menunjukan nilai regresi yang baik, $\mathrm{r}=0,9997$. Batas deteksi dan batas kuantifikasi yang didapat masingmasing adalah 0,54446 ppm dan 1,8148 ppm. Presisi metode dilihat dari \% RSD dengan hasil sebesar $0,27 \%$. Akurasi metode ditunjukan oleh nilai \% perolehan kembali dan menghasilkan 109,24 \% untuk analisis Timbal. Nilai yang dihasilkan ini dapat diterima dengan baik, sesuai dengan standard dan aturan yang ditetapkan. Prosedur ini kemudian digunakan untuk penentuan timbal pada sampel ikan tuna kemasan kaleng dan didapatkan hasil 0,6951 ppm untuk sampel A, 0,4634 ppm untuk sampel B dan 0,7073 ppm untuk sampel C.

\section{Pendahuluan}

Salah satu cara untuk menganalisis kandungan logam berat di laboratorium adalah dengan menggunakan Spektrofotometri Serapan Atom (SSA) dimana ini merupakan teknik yang cepat dan serbaguna untuk penentuan logam [1]. Oleh sebab itu, instrumen ini sangatlah cocok untuk digunakan menganalisis banyak sampel karena dapat diuji secara langsung namun yang lain diperlukan tahapan preparasi sebelum analisis [2].

Beberapa metode yang digunakan untuk preparasi sampel sebelum uji SSA adalah destruksi sampel basah dan kering. Akan tetapi 
metode ini memiliki kekurangan baik dari segi waktu, jumlah pelarut yang dipakai maupun tingkat kontaminasi yang tinggi [3].

Selain metode destruksi diatas, adapula metode destruksi berbantuan gelombang mikro (microwave digestion). Dalam metode ini sampel ditambahkan asam kuat dalam sistem tertutup yang menyebabkan terjadinya peningkatan suhu dan tekanan. Peningkatan suhu dan tekanan serta kondisi dalam $\mathrm{pH}$ rendah pada sampel menyebabkan peningkatan kecepatan dekomposisi termal dari sampel uji yang membuat logam menjadi larut. Teknik ini dibandingkan dengan yang lain, memiliki keuntungan seperti preparasi sampel yang cepat dan mengurangi resiko terkontaminasi [4].

Berbagai bahan yang digunakan untuk mengemas makanan antara lain adalah kaleng. Kaleng adalah pengemas yang terbuat dari lempeng besi yang disambung dengan solder menggunakan timah dan dilapisi dengan timbal. Ikan yang dikemas dalam kemasan kaleng dapat terkontaminasi dengan logam berat timbal yang merupakan komponn pembuat kaleng, Makanan kaleng dapat menyerap dari wadahnya baik timah, seng dan besi dari plat timah, serta timah dan timbal dari patrian [5].

Untuk mengetahui apakah suatu metode dapat digunakan sebagai metode standar maka diperlukan pengkajian terhadap metode tersebut. Validasi metode analisis merupakan langkah penting dalam mengontrol kualitas analisis kuantitatif. Upaya untuk memperoleh suatu metode yang valid memerlukan beberapa parameter yang harus dilakukan meliputi ketepatan (akurasi), ketelitian (presisi), linieritas, batas deteksi instrumen (IDL), batas deteksi dan batas kuantitasi metode (LOD dan LOQ), dan uji kekuatan metode (robustness) [6].

Timbal mempunyai sifat yang larut dalam asam, sehingga suasana asam yang ada pada ikan dalam kemasan kaleng memungkinkan larutnya timbal dari kaleng kedalam ikan yang dikemas. Kontaminasi timbal akan berbahaya bila masuk kedalam metabolisme tubuh, dalam jumlah kecil tidak berbahaya bagi manusia, namun jika jumlahnya melampaui batas dapat menyebabkan keracunan akut maupun kronis. Jika jumlah melebihi ambang batas yang telah ditetapkan oleh Badan Standar Nasional Indonesia.

Mempertimbangkan pentingnya preparasi sampel dan juga melihat akan bahaya logam timbal terhadap tubuh manusia, maka perlu untuk dilakukan penelitian yang meliputi optimasi terhadap metode preparasi sampel berbantuan gelombang mikro sehingga preparasi sampel ikan tuna kemasan kaleng mendapatkan hasil yang optimal dan analisis logam berat dari sampel ikan tuna kemasan kaleng terhidar dari kontaminasi. Hasil analisis logam dengan metode preparasi yang optimal juga akan memberikan informasi konsentrasi logam timbal dalam ikan tuna kemasan kaleng dengan akurat.

\section{Bahan dan Metode}

Bahan yang digunakan adalah $\left(\mathrm{HNO}_{3}\right)$ $65 \%$ for analysis EMSURE (Merck), asam sulfat $\left(\mathrm{H}_{2} \mathrm{SO}_{4}\right)$ pekat $95 \%$ (Merck), asam peroksida $\left(\mathrm{H}_{2} \mathrm{O}_{2}\right)$, aquades (water one), dan larutan standar $\mathrm{Pb}$ (II) (Merck-SRM) 1000 mg/L. Sampel dalam penelitian ini adalah ikan tuna kemasan kaleng beberapa merek yang beredar di pasaran kota Manado.

Alat yang digunakan adalah Instrumen Spektrofotometer Serapan Atom (SSA) Perkin Elmer PinAAcle 900F dengan parameter kondisi ditunjukan pada Tabel 1, Microwave MPS Titan 100 Perkin Elmer dengan 16 wadah digesti politetrafluoroetilena (PTFE) dan program seperti ditunjukan dalam Tabel 2, Lemari Asam, pipet mikro ukuran 100-1000 $\mu \mathrm{L}$ dan $50-250 \mu \mathrm{L}$, botol plastik untuk sampel, Labu ukur $50 \mathrm{ml}, 25 \mathrm{ml}, 100 \mathrm{ml}$ dan peralatan gelas laboratorium lainnya.

Tabel 1. Parameter kondisi SSA-nyala

\begin{tabular}{cccc}
\hline Logam & $\begin{array}{c}\text { Panjang } \\
\text { gelombang } \\
\text { (nm) }\end{array}$ & $\begin{array}{c}\text { Lebar } \\
\text { celah } \\
\text { (nm) }\end{array}$ & Nyala \\
\hline $\mathrm{Pb}$ & 283,31 & 0,7 & $\begin{array}{c}\text { Udara- } \\
\text { asetilena }\end{array}$ \\
\hline
\end{tabular}

Pengambilan sampel

Sampel ikan tuna kemasan kaleng diperoleh dari dari toko swalayan di Kota Manado, Provinsi Sulawesi Utara (Tabel 3). Sampel yang dipilih kemudian dibawa ke laboratorium kimia. 
Tabel 2. Program destruksi pilihan

\begin{tabular}{cccccc}
\hline Tahap & $\begin{array}{c}\text { Suhu } \\
\left({ }^{\circ} \mathbf{C}\right)\end{array}$ & $\begin{array}{c}\text { Tekanan } \\
\text { (barr) }\end{array}$ & Waktu ramp & $\begin{array}{c}\text { Waktu } \\
\text { Tahan }\end{array}$ & $\begin{array}{c}\text { Daya } \\
(\%)\end{array}$ \\
\hline 1 & 170 & 30 & 10 & 5 & 60 \\
2 & 200 & 30 & 1 & 20 & 70 \\
3 & 50 & 30 & 1 & 10 & 0 \\
4 & 50 & 60 & 0 & 0 & 0 \\
5 & 50 & 60 & 0 & 0 & 0 \\
\hline
\end{tabular}

Tabel 3. Karakteristik sampel yang diuji

\begin{tabular}{ccc}
\hline $\begin{array}{c}\text { Kode } \\
\text { sampel }\end{array}$ & $\begin{array}{c}\text { Jenis } \\
\text { ikan }\end{array}$ & Komposisi \\
\hline A & $\begin{array}{c}\text { Tuna } \\
\text { sambal } \\
\text { goreng }\end{array}$ & $\begin{array}{c}\text { Tuna (70\%), minyak } \\
\text { kelapa sawit, cabe, } \\
\text { air,b.merah, b.putih, } \\
\text { kemiri, garam, jahe, } \\
\text { gula }\end{array}$ \\
& Tuna & Tuna (70\%), minyak \\
B & dalam & kedelai, air, garam \\
& minyak & \\
C & Tuna & Tuna (70\%), minyak \\
& dalam & nabati, air, garam \\
\hline
\end{tabular}

Penentuan kombinasi asam optimal

Prosedur destruksi dengan bantuan gelombang mikro, melibatkan pemanasan dengan gelombang mikro dan menggunakan kombinasi asam $\mathrm{HNO}_{3}, \mathrm{H}_{2} \mathrm{SO}_{4}$, dan $\mathrm{H}_{2} \mathrm{O}_{2}$ untuk menghancurkan sampel. Sampel ikan yang telah disiapkan sebelumnya, masing-masing sebanyak 0,75 gram. Selanjutnya sampel masing-masing dimasukkan ke dalam vessel berbeda. Setiap vessel ditambahkan campuran asam dengan volume dan kombinasinya disajikan pada Tabel 4.

Tabel 4. Rancangan kombinasi asam yang digunakan

\begin{tabular}{cccc}
\hline Kombinasi & $\begin{array}{c}\mathrm{HNO}_{3} \\
(\mathbf{m L})\end{array}$ & $\begin{array}{c}\mathrm{H}_{2} \mathrm{O}_{2} \\
(\mathbf{m L})\end{array}$ & $\begin{array}{c}\mathrm{H}_{2} \mathbf{S O}_{4} \\
(\mathbf{m L})\end{array}$ \\
\hline 1 & 10 & 0 & 0 \\
2 & 9 & 0 & 1 \\
3 & 8 & 1 & 1 \\
4 & 7 & 1 & 2 \\
5 & 7 & 2 & 1 \\
6 & 6 & 2 & 2 \\
\hline
\end{tabular}

Larutan hasil destruksi kemudian diencerkan ke labu takar $25 \mathrm{~mL}$. Larutan sampel encer selajutnya ditentukan kadarnya menggunakan SSA nyala. Kombinasi optimal ditunjukan pada absorbansi terbesar.

\section{Uji validasi metode}

5 parameter validasi yang digunakan meliputi linearitas, $L O D$ dan $L O Q$, presisi dan akurasi karena parameter ini merupakan parameter dasar untuk uji validasi metode [7].

\section{Penentuan logam $\mathrm{Pb}$}

Sampel ikan tuna kemasan kaleng yang homogen, masing-masing sebanyak 0,75 gram, didestruksi menggunakan kombinasi asam optimal. Selanjutnya larutan hasil destruksi diencerkan dalam labu $25 \mathrm{~mL}$ dengan akuades dan dihomogenkan. Larutan sampel encer selajutnya ditentukan kadarnya menggunakan SSA nyala.

\section{Hasil dan Pembahasan}

Penentuan kombinasi asam optimal

Sampel yang telah didestruksi menggunakan 6 variasi kombinasi asam menghasilkan kualitas destruksi yang berbedabeda, lewat pengamatan fisik larutan hasil destruksi kombinasi asam 1, 2, dan 3 larutan berwarna hijau tua namun tidak jernih yang disebabkan sampel tidak terdestruksi sempurna. Sedangkan untuk kombinasi asam 4 , 5, dan 6 menghasilkan larutan sampel berwarna hijau muda yang jernih hal ini menunjukan bahwa sampel terdestruksi sempurna. Namun, untuk penentuan kombinasi asam optimal dari variasi kombinasi yang dirancang, dilihat juga dari absorbansi paling tinggi yang dihasilkan melalui analisis dengan SSA. Tabulasi data 
absorbansi untuk penentuan kombinasi optimal ditunjukan pada Tabel 5.

Tabel 5. Data absorbansi setiap variasi kombinasi asam

\begin{tabular}{|c|c|c|c|c|}
\hline \multirow{2}{*}{ Kombinasi } & \multicolumn{3}{|c|}{ Kombinasi asam } & \multirow{2}{*}{ A } \\
\hline & $\mathrm{HNO}_{3}$ & $\mathrm{H}_{2} \mathrm{O}_{2}$ & $\mathrm{H}_{2} \mathrm{SO}_{4}$ & \\
\hline 1 & 10 & 0 & 0 & $-0,0006$ \\
\hline 2 & 9 & 0 & 1 & 0,0017 \\
\hline 3 & 8 & 1 & 1 & 0,0015 \\
\hline 4 & 7 & 1 & 2 & 0,0039 \\
\hline 5 & 7 & 2 & 1 & 0,0020 \\
\hline 6 & 6 & 2 & 2 & 0,0041 \\
\hline
\end{tabular}

Dari hasil penentuan kombinasi asam optimum, kombinasi asam 1 yang hanya terdiri dari $\mathrm{HNO}_{3}$ memiliki nilai absorbansi paling rendah, hal ini dikarenakan $\mathrm{HNO}_{3}$ kurang kuat untuk merusak matriks sampel yang membebaskan timbal agar dapat terlarut sempurna. Kombinasi asam 2, 3, dan 5 dengan hadirnya $\mathrm{H}_{2} \mathrm{SO}_{4}$ sebanyak $1 \mathrm{~mL}$, ketiganya menunjukan nilai absorbansi yang tidak jauh berbeda. Namun ketika volume $\mathrm{H}_{2} \mathrm{SO}_{4}$ di naikan maka adanya kenaikan nilai absorbansi, terlebih lagi ketika volume $\mathrm{H}_{2} \mathrm{O}_{2}$ di tambah menjadi $2 \mathrm{~mL}$ seperti yang terjadi pada kombinasi asam 6.

Absorbansi dari kombinasi 6 ini menjadi yang paling tinggi, sehingga kombinasi asam 6 dengan perbandingan asam nitrat $\left(\mathrm{HNO}_{3}\right) 6 \mathrm{~mL}$ dan asam peroksida $\left(\mathrm{H}_{2} \mathrm{O}_{2}\right) 2 \mathrm{~mL}$ serta asam sulfat $\left(\mathrm{H}_{2} \mathrm{SO}_{4}\right) 2 \mathrm{~mL}$, dipilih sebagai kombinasi asam optimum untuk destruksi ikan tuna kemasan kaleng.

\section{Validasi metode}

Validasi metode analisis adalah suatu pekerjaan penilaian terhadap parameter tertentu, didasarkan pada percobaan laboratorium untuk membuktikan bahwa parameter tersebut memenuhi persyaratan untuk penggunaannya. Parameter validasi yang dilakukan yaitu, antara lain; Uji linearitas, Uji LOD (Limit Of Detection) \& LOQ (Limit Of Quantitation), Uji akurasi dan Uji presisi.

\section{Uji linearitas}

Pengujian

linearitas

metode

spektrofotometri serapan atom-nyala untuk logam timbal dilihat dari kurva kalibrasi yang dihasilkan dengan menguji deret larutan standar timbal menggunakan SSA, deret larutan standar yang digunakan ditunjukan pada Tabel 6. Dari kurva kalibrasi ini dihasilkan persamaan regresi $y=0,0082 x+0,0003$ dan nilai koefisien korelasi (r) adalah 0,9997. Kurva hasil pengukuran dapat di lihat pada Gambar 1.

ICH (International Conference on Harmonization) merekomendasikan nilai linearitas dapat diterima ketika koefisien regresi $\geq 0,997$ dengan minimal 5 variasi konsentrasi yang digunakan. Dibandingkan dengan nilai koefisien regresi dari logam timbal, menunjukan bahwa linearitas logam timbal dapat diterima.

Tabel 6. Absorbansi Seri Lar. Standar Timbal

\begin{tabular}{cc}
\hline Konsentrasi & $\begin{array}{c}\text { Absorbansi } \\
\text { (A) }\end{array}$ \\
\hline 0 & 0,0000 \\
4 & 0,0335 \\
8 & 0,0657 \\
12 & 0,0997 \\
16 & 0,1289 \\
20 & 0,1652 \\
\hline
\end{tabular}

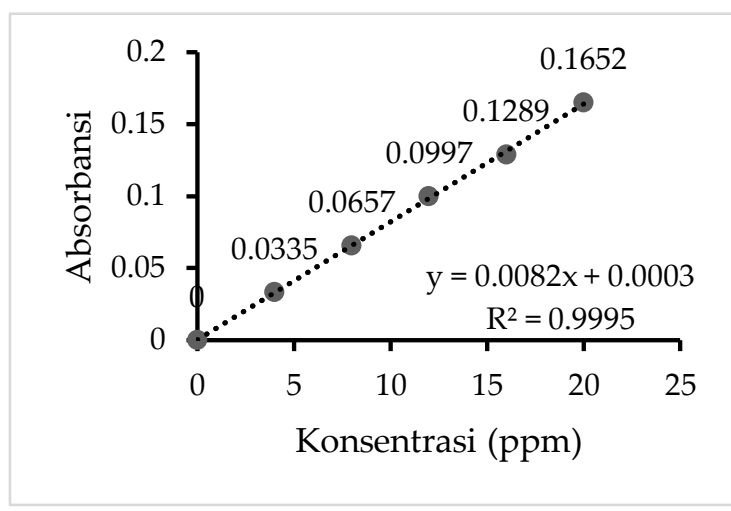

Gambar 1. Kurva kalibrasi Larutan Standar Timbal

\section{LOD dan $L O Q$}

Dari data yang diperoleh diketahui bahwa jumlah terkecil analit (logam timbal) dalam sampel yang masih dapat dideteksi adalah sebesar 0,54446 ppm, sedangkan batas kuantitasi yang masih dapat memberikan hasil yang teliti adalah sebesar 1,8148 ppm. 
Tabel 7. Tabulasi data uji presisi

\begin{tabular}{|c|c|c|c|c|c|c|c|c|c|}
\hline \multirow{2}{*}{ Konsentrasi } & \multicolumn{6}{|c|}{ Absorbansi } & \multirow{2}{*}{$\overline{\mathbf{A}}$} & \multirow{2}{*}{ SD } & \multirow{2}{*}{$\begin{array}{c}\% \\
\text { RSD }\end{array}$} \\
\hline & 1 & 2 & 3 & 4 & 5 & 6 & & & \\
\hline $\mathrm{Pb} 20$ ppm & 0,1807 & 0,1805 & 0,1807 & 0,1808 & 0,1811 & 0,1798 & 0,1806 & 0,0005 & 0,27 \\
\hline
\end{tabular}

Uji presisi

Uji presisi dilakukan pada logam timbal dengan mengukur satu konsentrasi sebanyak 6 kali pengulangan. Untuk logam timbal konsentrasi yang digunakan adalah 20 ppm. Tabulasi data dapat dilihat pada Tabel 7.

Walaupun merupakan larutan standar yang sama, nilai absorbansi yang dihasilkan dari uji presisi untuk konsentrasi 20 ppm dengan 6 kali pengulangan terlihat berbeda dengan hasil pengukuran untuk penentuan kurva kalibrasi. Hal ini dapat disebabkan karena perbedaan waktu uji untuk kurva kalibrasi dan presisi, sehingga kondisi larutan berubah dan kondisi alat yang berbeda misalnya tegangan listrik ataupun ketika penyemprotan larutan untuk atomisasi. Meski demikian, 6 nilai absorbansi yang dihasilkan untuk uji presisi ini tidak jauh berbeda satu sama lain. Sehingga menghasilkan nilai \% RSD yang cukup baik yakni $0,27 \%$ nilai ini memenuhi syarat untuk uji presisi yaitu $\leq 2 \%$. Nilai \% RSD yang baik ini menunjukan bahwa alat yang digunakan memiliki tingkat presisi yang baik untuk digunakan sebagai alat uji logam di laboratorium.

\section{Uji akurasi}

Uji akurasi metode dilakukan untuk melihat derajat kedekatan hasil analisis dengan kadar analit sebenarnya, hasilnya dinyatakan dalam bentuk persen perolehan kembali. Dalam penelitian ini, penentuan akurasi dilakukan dengan metode adisi standar, dimana 0,5 $\mathrm{ml}$ lar. standar $\mathrm{Pb}$ ditambahakan ke dalam $5 \mathrm{ml}$ sampel dalam labu $25 \mathrm{ml}$. Hasilnya berupa nilai absorbansi larutan sampel tanpa adisi larutan standar (larutan sampel, A1) dan nilai absorbansi larutan sampel dengan penambahan lar. standar (A2).Perhitungan konsentrasi analit (timbal) dalam larutan sampel menggunakan persamaan 1. Dimana, $\mathrm{A}_{1}=$ Absorbansi larutan sampel, $\mathrm{A}_{2}=$ Absorbansi larutan sampel dan larutan baku, $\mathrm{C}_{\mathrm{x}}=$ Konsentrasi analit dalam larutan sampel, $\mathrm{C}_{\mathrm{s}}=$ konsentrasi larutan baku, $\mathrm{V}_{\mathrm{x}}=$ Volume larutan sampel, $\mathrm{V}_{\mathrm{s}}=$ volume larutan baku. Sedangkan untuk menghitung Persen Recovery, digunakan persamaan 2. Dimana $\mathrm{C} 1$ = Konsentrasi analit dalam larutan sampel, C2 = konsentrasi dari analit dalam sampel, C3 = konsentrasi dari analit yang ditambahkan kedalam sampel.

$$
\begin{gathered}
C \mathrm{x}=\frac{A_{1} V_{S} C_{S}}{\left(A_{2}-A_{1}\right) V x} \\
\% \text { recovery }=\frac{(C 1-C 2)}{C 3} \times 100 \%
\end{gathered}
$$

Persen perolehan kembali yang didapat, sebagai mana yang ditampilkan dalam tabel 8 yaitu 109,24\%. Hasil ini menunjukan bahwa akurasi dari metode yang digunakan memenuhi syarat rentak akurasi yang ditetapkan atau direkomendasikan oleh AOAC yakni $75-120 \%$.

Tabel 8. Tabulasi data uji akurasi Timbal

\begin{tabular}{ccccc}
\hline Sampel & Cs & $\overline{\mathbf{A}}$ & Cx & $\begin{array}{c}\text { \% } \\
\text { Recovery }\end{array}$ \\
\hline A & 0 & 0,0060 & 1,1320 & 109,24 \\
A & 20 & 0,0166 & & \\
\hline
\end{tabular}

\section{Penentuan kadar $\mathrm{Pb}$}

Setelah melalui tahap uji validasi dan mendapatkan hasil yang baik (valid), metode ini diterapkan untuk penentuan logam berat timbal pada sampel ikan tuna kemasan kaleng. 3 merek ikan tuna kemasan kaleng dipilih sebagai sampel kemudian masing-masing didestruksi sebanyak 2 kali pengulangan (duplo). Berdasarkan analisis spektrofotometer serapan atom nyala (SSA-nyala) dan perhitungan dengan aplikasi Excel, didapatkan hasil seperti yang ditunjukan pada Tabel 9.

Konsentrasi logam timbal dari tiap sampel menunjukan perbedaan yang cukup besar diantara sampel B dengan sampel A dan C 
seperti yang ditunjukan pada diagram di Gambar 2.

Tabel 9. Data konsentrasi logam timbal pada sampel ikan tuna kemasan kaleng

\begin{tabular}{|c|c|c|c|c|}
\hline \multirow{2}{*}{ Sampel } & \multicolumn{2}{|c|}{ Absorbansi } & \multirow{2}{*}{$\overline{\mathbf{A}}$} & \multirow{2}{*}{$\underset{(\mathrm{ppm})}{\overline{\mathbf{x}}}$} \\
\hline & 1 & 2 & & \\
\hline A & 0,0059 & 0,0060 & 0,0060 & 0,6951 \\
\hline B & 0,0038 & 0,0043 & 0,0041 & 0,4634 \\
\hline C & 0,0060 & 0,0062 & 0,0061 & 0,7073 \\
\hline
\end{tabular}

Dari hasil penelitian ini, konsentrasi logam timbal ditemukan cukup tinggi untuk semua sampel yaitu masing-masing 0,6951 ppm untuk sampel A, 0,4634 ppm untuk sampel B dan untuk sampel C 0,7073 ppm.

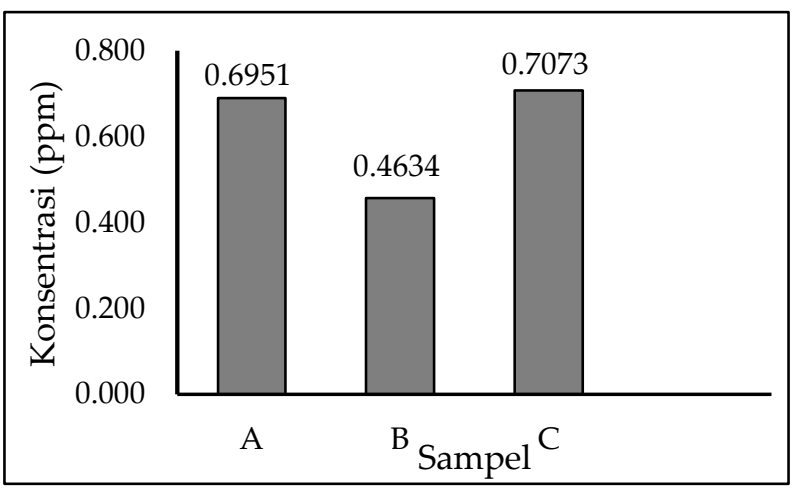

Gambar 2. Diagram Konsentrasi Timbal Pada Sampel Ikan Tuna Kemasan Kaleng

Batas maksimum level timbal untuk ikan dan produk olahan ikan yang diijinkan adalah 0,2000 ppm, tetapi oleh Badan POM Indonesia menetapkan batas maksimum logam timbal dalam ikan dan produk olahan ikan adalah 0,4000 ppm [8,9]. Pada penelitian ini, konsentrasi logam timbal dalam sampel A, B dan $\mathrm{C}$ telah melebihi batas yang telah ditetapkan yakni $>0,4000 \mathrm{ppm}$. Tingginya konsentrasi timbal dalam semua sampel yang telah diuji dipengaruhi oleh kemasan sampel yaitu kaleng, dimana dalam proses pembuatannya telah terkontaminasi logam. Soldering dalam proses pembuatan kaleng untuk kemasan ikan tuna menjadi sumber kontaminasi logam timbal, sehingga meningkatkan konsentrasi timbal dalam ikan tuna yang dikemas [10]. Selain itu, spesies ikan tuna merupakan ikan predator yang dapat mengakumulasi logam berat dalam jumlah yang besar [11].

Interaksi ikan tuna dengan kemasannya (kaleng) memang tidak dapat dihindarkan. Namun, jika semakin lama interaksi antara ikan tuna dengan kemasanya, kemungkinan konsentrasi logam akan meningkat.

Hefinda, dkk. 2014, menemukan bahwa lama waktu penyimpanan mempengaruhi konsentrasi logam timbal dalam ikan atau bahan yang dikemas dengan kaleng. Hal ini dikarenakan semakin banyak $\mathrm{H}^{+}$yang mengoksidasi logam dalam bahan pengemas kaleng, sehingga akan semakin banyak logam yang teroksidasi serta semakin banyak pula logam yang dapat larut dalam zat pengoksidasi [12].

\section{Kesimpulan}

Berdasarkan kualitas hasil destruksi yang diamati melalui parameter absorbansi, kombinasi asam yang optimal ditunjukan dengan nilai absorbansi yang paling tinggi. Dipilih kombinasi 6 dengan komposisi $\mathrm{HNO}_{3}$ : $\mathrm{H}_{2} \mathrm{O}_{2}: \mathrm{H}_{2} \mathrm{SO}_{4}=6: 2: 2$ (mL) sebagai kombinasi asam optimal untuk preparasi sampel berbantuan gelombang mikro. Berdasarkan perolehan nilai linearitas, presisi, akurasi, LOD dan LOQ yang menunjukan nilai yang dapat diterima. Dengan demikian dapat dinyatakan bahwa metode preparasi yang dikembangkan dalam penelitian ini layak atau valid untuk analisis logam timbal menggunakan spektrofotometer serapan atom nyala. Konsentrasi logam timbal ditemukan cukup tinggi dan telah melewati batas yang ditetapkan untuk semua sampel (A, B dan C) yaitu masing-masing 0,6951 ppm untuk sampel A, 0,4634 ppm untuk sampel B dan 0,7073 ppm untuk sampel C. Kualitas kemasan kaleng yang digunakan, waktu penyimpanan dan ikan tuna yang digunakan serta kondisi ikan tuna dalam kemasan kaleng dapat mempengaruhi konsentrasi logam timbal dalam ikan tuna.

\section{Daftar Pustaka}

1. Farrukh, M.A. Atomic Absorption Spectroscopy; 2012; ISBN 978-953-307-817-5.

2. Cantle, J.E. Atomic absorption spectrometry; Elsevier, 1986; 
3. Haswell, S.J. Atomic Absorption Spectrometry; 1st ed.; Elsevier Science, 1991; Vol. 5; ISBN 978-0-08-093397-9.

4. Matusiewicz, H. Wet digestion methods. Comprehensive Analytical Chemistry 2003, 41, 193-233, doi:10.1016/S0166-526X(03)410064.

5. Cahyadi, W. Bahaya Pencemaran Timbal pada Makanan dan Minuman; 2004;

6. Abarca, A.; Canfranc, E.; Sierra, I.; Marina, M.L. A validated flame AAS method for determining magnesium in a multivitamin pharmaceutical preparation. Journal of pharmaceutical and biomedical analysis 2001, 25, 941-945.

7. Riyanto Validasi \& Verifikasi Metode Uji: Sesuai dengan ISO/IEC 17025 Laboratorium Pengujian dan Kalibrasi; 1st ed.; deepublish: Yogyakarta, 2014;

8. The Commission of the European Communities amending Regulation (EC) No 466/2001 as regards heavy metals; 2005;

9. BPOM Batas Maksimum Cemaran Logam Berat; 2018;

10. Mol, S. Levels of selected trace metals in canned tuna fish produced in Turkey. Journal of Food Composition and Analysis 2011, 24, 66-69.

11. Kowalska, G.; Pankiewicz, U.; Kowalski, R. Determination of the Level of Selected Elements in Canned Meat and Fish and Risk Assessment for Consumer Health. Journal of Analytical Methods in Chemistry 2020, 2020.

12. Erfiandika, H. Analisis Kadar $\mathrm{Pb}$ dan $\mathrm{Cu}$ pada Ikan serta Saus Kemasan Kaleng Terhadap Lama Penyimpanan, Universitas Jember: Jember, 2014.

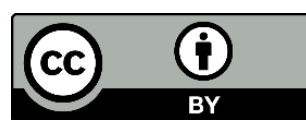

(C) 2020 by the authors. Licensee Fullerene Journal Of Chem. This article is an open access article distributed under the terms and conditions of the Creative Commons Attribution (CC BY) license

(http://creativecommons.org/licenses/by/4.0/). 